This item was submitted to Loughborough's Research Repository by the author.

Items in Figshare are protected by copyright, with all rights reserved, unless otherwise indicated.

\title{
Healthcare self-management tools: promotion or prevention regulatory focus? A scale (PR-PV) development and validation
}

PLEASE CITE THE PUBLISHED VERSION

http://dx.doi.org/10.1080/10696679.2015.980174

\section{PUBLISHER}

(C) Taylor and Francis Group

\section{VERSION}

AM (Accepted Manuscript)

\section{PUBLISHER STATEMENT}

This work is made available according to the conditions of the Creative Commons Attribution-NonCommercialNoDerivatives 4.0 International (CC BY-NC-ND 4.0) licence. Full details of this licence are available at: https://creativecommons.org/licenses/by-nc-nd/4.0/

\section{LICENCE}

CC BY-NC-ND 4.0

\section{REPOSITORY RECORD}

Nieroda, Marzena, Kathy Keeling, and Debbie I. Keeling. 2019. "Healthcare Self-management Tools: Promotion or Prevention Regulatory Focus? A Scale (PR-PV) Development and Validation”. figshare. https://hdl.handle.net/2134/17115. 
Healthcare Self-Management Tools: Promotion or Prevention Regulatory Focus? A Scale (PR-PV) Development and Validation

\section{JMTP Manuscript: 14-0102-755}

\section{Marzena Nieroda}

Doctoral candidate

Manchester Business School, University of Manchester,

Room 5.12 MBS West

Booth Street West, Manchester, M15 6PB, UK

Tel: +44 (0) 1619643864

Mobile: (+44) 07739873221

Fax: +44 (0) 1612756357

Email: marzena.nieroda@.mbs.ac.uk

\section{Kathleen Keeling}

Associate Professor in Research Methods and Statistics Manchester Business School, University of Manchester, Room 3.37 MBS West

Booth Street West, Manchester, M15 6PB, UK

Tel: +44 (0) 1612750948

Fax: +44(0) 1612756357

Email: kathy.keeling@manchester.ac.uk

\section{Debbie Keeling}

Associate Professor in Marketing

School of Business and Economics, Loughborough University

BE.1.29 (Sir Richard Morris Building)

Leicestershire, LE11 3TU, UK

Tel: +44 (0)150922 3117

Fax: +44(0) 1612756357

Email: d.i.keeling@lboro.ac.uk 
Healthcare Self-Management Tools: Promotion or Prevention Regulatory Focus? A Scale (PR-PV) Development and Validation

\title{
JMTP Manuscript: 14-0102-755
}

\begin{abstract}
Health self- management tools, believed to provide effective and cost-efficient healthcare, are often rejected by consumers. Regulatory focus theory (Higgins 2014) could facilitate adoption patterns of such tools by positioning adoption as matching/mismatching individual motivational concern: promotion/prevention focus. This research proposes that people perceive products as inherently promotion or prevention orientated, and matching person orientation to product orientation enhances tool uptake. The paper outlines the development of a scale measuring promotion/ prevention characteristics of objects, providing evidence for dimensionality, convergent, discriminant and predictive validity. The resulting PM-PV scale allows promotion/prevention categorization for personal healthcare tools with potential for wider generalization.
\end{abstract}


Healthcare costs are rising globally, as are the significant social pressures to provide effective care for an aging population and other vulnerable groups such as people with chronic disorders. This has led some to hope that technology is "the catalyst that can rapidly transform healthcare and the practice of medicine” (Park and Jayaraman 2003 p. 41). Emerging computer or mobile-based technologies facilitate both prevention of future health problems and everyday health self-management of chronic conditions. Such tools can offer advantages in terms of costs and health outcomes if implemented at an individual level (Park and Jayaraman 2003; Fox et al. 2013). For example, Carter et al. (2013) find that mobile tracking gives a $40 \%$ advantage for retention of weight monitoring behavior over pen and paper methods. Fox et al. (2013) report that 55\% of people state use of tracking technologies had an impact on their overall health, $40 \%$ reported that it changed their overall approach to health, 33\% felt able to question medical professionals and 25\% believed it affected a treatment decision.

There are 16,275 (and growing) consumer-centered mobile applications with ' $a$ legitimate health function’ currently available (Aitken and Gauntlett 2013). This suggests a strong motivation to proactively develop e-Health tools for self-management amongst stakeholder groups, such as developers, healthcare professionals and policymakers (Reilly 2012). Notwithstanding, e-Health technologies are not widely adopted by individuals. Consequently, the realization of the benefits to both consumers and other stakeholders is limited. The Ruder Finn study (2013) found that only 35\% of internet-enabled mobile devices users were interested in using a personal mobile healthcare application, and less than half of those (16\%) actually accessed health applications regularly. Reasons for non-use include beliefs about (lack of) usefulness (9\%), (lack of) relevance (27\%) and different information acquisition preferences (26\%). Such figures indicate that at least a part of the problem lies in not understanding or believing that personal healthcare tools can help users reach their health 
goals. Consequently, there is a need to understand the role that e-Health tools play in helping consumers reach their health goals to help achieve impactful adoption rates.

Regulatory focus theory (RFT) (Higgins 2014) provides a potential understanding of how individual differences in health goal pursuit could affect healthcare tool use. This theory proposes that, through a promotion focus (needs for accomplishment) or prevention focus (needs for safety), individuals prioritize goal pursuit strategies leading to preferences for different products and services to support their goals. Through the lens of RFT, we define self-care and well-being as the final goals while e-Health tools are promotion or prevention orientated means to reach those goals. Findings from regulatory fit theory (RF), an extension of RFT, suggest that if tools could be matched to individual customer goal orientation then tool adoption could be increased. For example, Spiegel, Grant-Pillow and Higgins (2004) report a $20 \%$ advantage for fruit and vegetables consumption achieved from matching either a promotion or prevention orientated message to the consumer's individual foci. We believe that low adoption rates may be at least in part due to 'one size fits all' approaches that are incompatible with consumers' needs (Hortensius et al. 2012).

However, while we understand how important these individual goal pursuit strategies are to consumers, relatively little is known about how to recognize promotion or prevention fitted strategies, products or services. For the individual consumer orientation, a wellresearched scale exists (Higgins et al. 2001), but its nature makes it ineligible to measure regulatory focus attributes of products or services. There is no similar measure for the evaluation of the inherent promotion or prevention characteristics of products or services, such as e-Health tools. The lack of such a measure hinders appropriate e-Health tool recommendations, adoption and research that could inform development of new tools.

The aim of this paper is to build on the theoretical underpinnings of RFT to develop and validate a scale measuring promotion or prevention characteristics of different e-Health 
tools to enable researchers and practitioners to reliably and simply distinguish different tools. The specific objectives are: 1) provision of a conceptual basis for development of such a scale based on individual motivational state; 2) development of a promotion-prevention (PM-PV) scale for e-Health tools following the guidelines of Churchill (1969) and DeVellis (2011), and 3) discussion of managerial implications of the provision of such a scale to involved stakeholders.

In practice, the scale would enable customization of e-Health tool recommendations and potential improvements in adoption. For instance, medical practices could verify consumers' individual foci then recommend tools matching this individual orientation. Such recommendations could advance adoption of the tools and lead to improved health outcomes. Further, the scale is an important contribution to regulatory focus theory, as it provides theoretical and empirical grounds for goal orientation based tool/product differentiation (so far only implied based on a few experimental results). Such a contribution is a building block for further research as it can simplify and advance experimental designs aimed at evaluating various effects of regulatory fit. It also can provide appropriate manipulation checks questions for verification of the promotion and prevention nature of goal pursuit strategies.

\section{CONCEPTUAL DEVELOPMENT}

In discussing the promotion and prevention concepts and providing theoretical grounds for the scale development we identify (a) the characteristics of promotion and prevention focus from the individual perspective, (b) evidence that products can have a promotion or prevention nature; the evidence so far inferred from experimental findings; and, later in the discussion section, (c) applications of the scale if developed.

\section{Characteristics of Regulatory Focus Theory}

Regulatory focus theory (RFT) (Higgins 1998) recognizes two different motivational systems that guide consumer behavior and goal pursuit. These two systems, named promotion and 
prevention, prioritize and address different types of needs. Promotion focus is concerned with satisfying needs for accomplishment or nurturance, and tends to be active during the pursuit of dreams, wishes and aspirations (Pham and Chang 2010). Promotion oriented individuals are more sensitive to the presence or absence of positive outcomes, and tend to use approach strategies to achieve those gains (e.g., studying extra material in order to get an A in the test; Avnet and Higgins 2006). According to Molden, Lee and Higgins (2008), for promotion oriented individuals gains are accompanied by emotions of happiness and excitement, while feelings of sadness accompany non-gains.

A prevention focus on the other hand is concerned with satisfying protection and security needs and is more active during pursuit of duties, responsibilities or obligations. Prevention oriented individuals are sensitive to the presence or absence of negative outcomes, and tend to use avoidance strategies to prevent those losses (e.g., avoiding going out the night before the test as this might impact on getting an A in the test; Avnet and Higgins 2006). Prevention oriented individuals experience non-losses with a feeling of calmness, while losses can lead them to anxiety and anger (Molden, Lee and Higgins 2008). Table 1 (left hand column) presents a summary of the chronic characteristics assembled from the literature.

\section{Promotion or Prevention Function of Different Products}

Regulatory focus and fit research supports our argument that different products or behaviors can help individuals meet needs for accomplishment by supporting approach goal pursuit strategies to achieve positive outcomes, or meet needs for security by helping avoid losses and providing vigilant, avoidance strategies. Promotion or prevention characteristics of products have been so far evaluated in experimental pre-tests based on definitions or single question evaluations (Ku, Kuo and Kuo 2012, Keeling et al. 2013) and confirmed later in experimental designs. There is significant experimental evidence that a match between chronic/primed goal orientation and an inferred (but not reliably measured) product orientation creates the 
effects of regulatory fit (RF) (Higgins 2006), such as, 'feeling right' about and further engagement with goal pursuit, positive goal evaluations, affective reactions, enhanced intentions and behavior (Higgins et al. 2003, Daryanto et al. 2010). Zhou and Pham (2004) find that levels of investment in financial products and services (e.g., trading account vs. mutual fund) offering either nurturance or security benefits differ as a function of match/mismatch of a service with an appropriate gain or loss framed message. Micu and Chowdhury (2010) find more effective advertising results through matching hedonic and utilitarian products appropriately with promotion versus prevention focused advertisements. The inference is that (at least the perception of) promotion and prevention characteristics can be transferred to products and services.

Thus, differently oriented products will suit different individual orientations during the goal pursuit process. Accepting this to be the case, table 1 sets out the proposed relationships between the individual differences in promotion and prevention orientation and theoretically suggested (perceived) attributes of matching products/behaviors.

Place Table 1 about here

\section{How to Differentiate Individuals and Tools based on Goal Orientation?}

The most common measurement used for distinguishing between promotion and prevention oriented individuals is the Regulatory Focus Questionnaire (RFQ) (Higgins 2001). The questionnaire consists of 11 items evaluating a participant's history of promotion and prevention success and failure, with 6 items belonging to the promotion scale and 5 items belonging to the prevention scale. Some of the RFQ items are: 'Growing up, did you ever act in ways that your parents thought were objectionable?' or 'Not being careful enough has gotten me into trouble at times'. The RFQ can be computed as a single categorical variable 
distinguishing between promotion and prevention focus by using a median split after calculating the difference between promotion and prevention scores (Cesario, Grant, Higgins 2004). As this scale evaluates an individual's history of promotion or prevention activities, it is not applicable to the evaluation of promotion or prevention strategies or products.

In an endeavor to add value to existing research and to enable tool differentiation without the experimental verification of creating fit conditions, this research aims to develop a scale that could easily distinguish promotion from prevention tools. Taking the reviewed literature in table 1 as our starting point, we define promotion/prevention orientated health products as products meeting user needs for accomplishment/safety relative to their health. Use of a promotion orientated health tool is associated with approaching gains (happiness) resulting from successful goal pursuit relative to a user's health (e.g. health improvement). Use of a prevention orientated health tool is associated with avoiding losses (disappointment) that could result from failure in goal pursuit relative to a user's health (e.g., health deterioration) (see table 2). Identifying both an individual orientation and a product orientation enables us to match individual and product type. In practice, such matching should enable increased rates of adoption of e-Health tools with resulting potential for health benefits. The relevance of such matching is explored in the discussion section.

\section{SCALE DEVELOPMENT}

The steps used in development of our scale measuring the promotion (PM) and prevention (PV) characteristics of healthcare products are illustrated in figure 1. The context of this research is the adoption of e-Health tools typical of current offerings, ranging from activity recording wristbands to platforms for online patient/family support. The approach follows Churchill’s (1979) and DeVellis (2011) recommendations for scale development, incorporating the precautions advocated by Zaichkowsky (1985) and Hardesty and Bearden (2004) to achieve valid data collection processes, sample sizes and data analyses. 
Place Figure 1 about here

All studies except study 1 involved a sample from the online panel of Amazon Mechanical Turk (AMT). Research supports the use of samples recruited from AMT for the following reasons: a) samples are more representative of the USA population than commonly used convenience student samples, b) successful replication of existing studies with the samples obtained from AMT indicate the reliability of the data (Berinsky, Huber and Lenz 2012) and, c) data are of high quality when using 'high-reputation' respondents (Peer, Vosgerau, and Acquisti 2013). Consequently, we recruited only respondents with high reputation (scoring 98\% or higher in task acceptance rate), who had performed less than 500 tasks (to avoid professional survey takers), residing in the USA. The payment received for participation in the studies was $\$ 0.75$, a typical value for AMT workers (Paolacci, Chandler and Ipeirotis 2010) and adequate as Paolacci, Chandler and Ipeirotis (2010) show that even in case of very low payment $(\$ 0.10)$, AMT participants are as attentive to the instructions as are participants from traditional sources.

\section{Study 1a Validation of the Concept: Health Support Tool Categorization Task}

Before moving to actual scale development processes it was vital to confirm our fundamental proposition that different tools can be classified as promotion or prevention orientated by prospective users. In study 1a, 17 participants evaluated and categorized 19 different health management tools as promotion, prevention or neutral focused based on provided definitions of promotion and prevention focus (see table 2). Purposeful sampling amongst doctoral students and faculty of a large university followed by snowball sampling out to a wider network provided the participants for this study. Participants intentionally covered a range of ages (24-57), gender (58\% female: 42\% male) occupations, experience with e-Health tools 
and two health systems (i.e., USA and UK). The choice of tools came from two sources: i) the Google Play store (https://play.google.com/store/apps) on the basis of high ratings, high popularity and a range of functionality that would appeal to different needs, e.g., weight management, disease management and health information search, ii) websites and other tools from Google search results for the most popular health-related tools and websites serving different health self-management purposes. After tool selection, removal of branding avoided any contamination of results with brand associations. In further data analysis, based on the highest consistency in categorizations, 10 tools (see the appendix) emerged showing the strongest promotion (4), prevention (4), and neutral (2) characteristics. The tools were mobile applications and websites/platforms: (promotion orientated) (1) weight management, (2) activity wristband , (3) mapping runs, (4) working out, (prevention orientated) (5) body scanner, (6) health information application, (7) Personal Health Records (PHR) patient/family support online communities, (8) patient/disease specific support, and (neutral) (9) Medical reference application, (10) Online community for patient support . This initial categorization also served as a basis for a predictive validity study (study 4; discussed later).

Place Table 2 about here

\section{Studies 1b, 2 and 3: Item Generation and Purification}

The objective of this research was to develop a scale that could reliably differentiate between promotion/prevention products and services. We employed three studies to generate and identify the most relevant items for this scale. At the initial item generation stage we followed DeVellis (2011) and concentrated on the exhaustiveness of items covered. Item generation derived from the proposed characteristics identified from the conceptual foundations research in the existing literature summarized in table 1 (Higgins et al. 2001; Summerville and Roese 
2008; Pham and Chang 2010) together with the data from a qualitative study (1b), which helped us to produce potential items for the healthcare context and made certain that the tenets of regulatory focus theory were understood by a typical consumer.

In the qualitative study (1b), following the recommendations of DeVellis (2011), 17 participants explained why they evaluated and categorized 19 different e-Health tools as promotion, prevention or neutral based on the definitions of promotion and prevention focus provided (see table 2). Agreement between the conceptual foundations (see table 1) and statements obtained in the content analysis of these qualitative data (Dabholkar, Thorpe and Rentz 1995) helped 3 judges (members of the marketing department at a large research university) to identify 21 scale items representing either a promotion (9 items) or prevention (12 items) focus. The initial item pool was purposely larger than the probable final number of items as DeVellis (2011, p.80) advises a large item pool helps guard against poor internal consistency of a scale.

Studies 2 and 3 verified the face and content validity of the initially developed items, following recommendations of Malhotra (1981), DeVellis (2011) and supported by Hardesty and Bearden (2004). Judges for both studies (study 1: n=21, study 2: $n=31$ ) were recruited through AMT. The sample sizes are consistent with those in similar studies summarized by Hardesty and Bearden (2004), where sample sizes for judges varied between 5 and 52, with the majority of groups consisting of less than 30 judges.

Following the DeVellis (2011) recommendations, in study 2, twenty-one US adults judged the face and content validity of the original 21 items. The procedure involved judges placing scale items into 4 categories (promotion, prevention, neutral, both) based on prevention and promotion orientation definitions presented in study 1 (table 2), a procedure supported by Hardesty and Bearden (2004). Hardesty and Bearden (2004) describe three different strategies for item retention, including sum scores of ratings where at least one judge 
has to consider the item at least somewhat representative of the construct and the 'complete' strategy where a set percentage of judges must consider the item completely representative. With 21 judges, the former strategy is likely to be too lenient, so the latter strategy is more appropriate. Hardesty and Bearden (2004) report an example threshold of 50\% agreement. However, recent papers (using a smaller number of judges than the present study) set the threshold higher, at between 64-66\% (Brocato, Voorhees, and Baker 2012). Setting the threshold to $60 \%$ to allow for the larger number of judges, 13 items passed this requirement. Additionally, we replaced (by rewording and simplifying) 4 items considered relevant for theoretical face validity that did not pass this test but were described as being difficult to understand by some respondents, resulting in 17 remaining items (8 promotion: 9 prevention).

In study 3, these 17 items with rewordings were again categorized in line with promotion and prevention definitions (see table 2) but by a different set of 31 US adults. In terms of promotion (PM) - prevention (PV) categorization, the results were acceptable as 68\% of judges categorized 12 items as expected, another 4 items were categorized as expected by between 55 and $67 \%$ of judges, and 1 item was not categorized as expected by more than $50 \%$ of judges. We also asked for suggestions for item improvement, as recommended by DeVellis (2011). At this stage, retention was thought important for covering the theoretical and conceptual bases of the scale (see table 1). On this basis, for strengthening face validity all the items were kept for further analysis, but with changes in wording as recommended by judges (see table 3). This approach of maintaining items with lower level of agreement to strengthen face validity is consistent with previous research (Zaichkowsky 1985).

\section{Study 4: Initial Validation}

The aim of study 4 is three-fold, firstly to evaluate the latent structure of the proposed scale items and secondly, to evaluate convergent validity, and thirdly, to assess the ability of the PM-PV scale to distinguish between characteristics of different tools for health management. 


\section{Data Collection}

In order to confirm the characteristics of the scale developed through generation and an initial item reduction process, the first of two larger studies was conducted. At $n=210$, this exceeds popular recommendations for factor analysis, such as, 10 cases to each item or absolute sizes of over 200 cases (Arrindell and van der Ende, 1985; p. 166). Communalities all exceeded .5, so a sample size of $100-200$ is sufficient for recovery of population factors in sample data (MacCallum et al. 1999). DeVellis (2011) recognizes similar samples as acceptable in cases where scales have a smaller pool of items and the sample represents the intended user. Furthermore, other scale validation studies use similar sample sizes, for instance Ramsey and Deeter-Schmelz (2008) and Hoffman, Mai, and Smirnova (2011). The sample for study 4 consisted of US males (70\%) and females (30\%). The age range was 18 to 72 years (mean 27 years). There were no systematic differences by gender or age.

To achieve the 3 main aims of study 4 , the respondents were randomly assigned to one of 10 groups, where each group was presented with information about one of the 10 tools identified above. Information consisted of a short description of the tool (see the appendix) and an image of the tool. Respondents were asked to evaluate the tool using the proposed PMPV scale items. Answers to PM-PV items were then grouped as a nested file for PCA and CFA analysis. For a test of convergent validity, the promotion and prevention tools should not differ in perceptions of effectiveness (Higgins et al. 2003), thus we include a scale for effectiveness applied in relation to different tools.

\section{Evaluation of the Latent Structure -Principal Component Analysis}

All the items were first assessed in an examination for low correlations (below .60) of the average corrected item-to-total correlation (DeVellis 2011), followed by principal component analysis (PCA) with oblique rotation, eigenvalue above 1 criterion. The PCA resulted in a three factor solution with one item, ('Take responsibility for their own health') loading on the 
theoretically 'wrong' factor (promotion). This item was removed. The first two factors represented the prevention and promotion focus, the third (and unexpected factor; 2 items) represented the theoretical underpinning for emotional aspects in prevention focus. The emotional aspect is not included in the original RFQ scales and has so far received mixed empirical support in the literature (Summerville and Roese 2008). For instance, emotions in result of fit or non-fit are often considered as a separate variable (Cesario and Higgins 2008). Coupled with item-total correlations below .60, the evidence indicated removal of these two items. To strengthen theoretical correspondence between the two new scales, we also removed the two emotion items on the promotion scale (excitement, feel happy). The PCA results on the remaining 12 items with respective loadings (plus the 5 eliminated items) are presented in table 3.

\section{Place Table 3 about here}

\section{Evaluation of the Latent Structure - Confirmatory Factor Analysis}

A subsequent confirmatory factor analysis (CFA) (Brocato, Voorhees, and Baker 2012) suggested that the two factor solution provides a good fit, but that a small respecification of the scale might be needed. Considerations of typical scale development indices, such as itemto-total correlations, internal consistency (reliability), AVEs and unidimensionality (DeVellis 2011), suggested reducing the PV scale to 5 items. The low loading and the low AVE (53\%) of item 2 ('Reduce health concerns') on the PV scale (see table 4 and 5), plus high scores on the diagnostics of standardized residuals and modification indices indicated that this item be removed, resulting in a good fit on a range of indices $\left(\chi^{2}=75.711, \mathrm{df}=43\left(\chi^{2} / \mathrm{df} 1.76\right)\right.$, $\mathrm{CFI}=.974, \mathrm{IFI}=.974, \mathrm{GFI}=.935$ and $\mathrm{RMSEA}=.060, \mathrm{PCLOSE}=.212)$. This removal was not considered to compromise the theoretical basis (see table 1) for the prevention dimension of 
the scale. Thus, the final solution came to 6 PM and 5 PV items. A complete listing of remaining 11 items is provided in table 4 , alongside item statistics.

\section{Place Table 4 about here}

\section{Construct Validation}

To check validity and reliability of the dimensions we followed the procedure recommended by Gerbing and Anderson (1988). First, we assessed the dimensionality of PM-PV dimensions by comparison of the unidimensional model fit to the 2-factor proposed model fit. The two factor solution $\left(\chi^{2}=75.711, \mathrm{df}=43, \chi^{2} / \mathrm{df} 1.76\right)$, provided a significantly better fit than the unidimensional model $\left(\chi^{2}=311.997, \mathrm{df}=44, \chi^{2} / \mathrm{df} 7.09\right)$. The standardized residuals and modification indices diagnostics did not suggest a need for further respecification. Then, we determined convergent and discriminant validity, followed by evaluation of reliability of the scales.

Loadings of individual items on the respective constructs provided assessment of the convergent validity of the constructs. As presented in table 4, all items load highly and significantly on their specified constructs. As presented in table 5, the calculated AVE for each construct exceeds the recommended .50 suggesting that the items reliably represent each construct.

Place Table 5 about here

The next step was assessing discriminant validity of the scales through an initial assessment of the correlations between the two scales, and followed by an assessment of appropriate model statistics. There was moderate correlation between PM and PV $\left(r=.62 ; r^{2}=.38\right)$, a low 
enough shared variance to suggest discriminant validity. Additionally, comparison of the AVE of both constructs to the squared correlation between the two constructs revealed that the AVE estimates (.57 and .60) are greater than the squared correlation $\left(r^{2}=.38\right)$ (Fornell and Larcker 1981). These results indicate that the PM-PV measures are distinct but correlated through a relationship to a common higher-order construct.

We calculated the construct reliability based on standardized factor loadings and error variances (table 5). For both scales, the reliability assessed exceeded .70 (Hair et al. 2008), ranging from .87 to .90 (see table 5). Overall, all the measures and assessment steps support a view that the PM-PV scales meet the standards for construct validation.

\section{Convergent Validity}

For convergent validity, the promotion and prevention tools should not differ in perceptions of effectiveness. In study 4 there were 10 tools used, and 3 of them had promotion characteristics and 3 had prevention characteristics. To indicate the expected relationship between PM, PV and effectiveness scores, we use scores for 6 of these tools (see table 7). Both PM and PV showed a relatively high positive and essentially similar relationship with the scale of effectiveness (see table 7 for details) indicating convergent validity. A non significant Z-test for the significance of the difference between both coefficients $(\mathrm{Z}=.56, \mathrm{p}=$ .577) supports this conclusion that both PM and PV scales share a similar relationship with the scale of effectiveness.

\section{Predictive Validity:}

Voss et al. (2003) provided the basis for evaluating predictive validity. The first step (study 1a) demonstrated initial confirmation that potential users do perceive different tools for health management as having predominantly promotion or prevention characteristics and the level of agreement of a perceptual rating of a set of tools on this basis. Participants categorized each of the 10 tools as having mostly promotion or prevention characteristics, or 
being neutral. In this step, we test whether the derived PM-PV scales can discriminate among such health management tools in a similar way. If they do, we can expect the data from study 4 regarding the ratings for each tool on the PM-PV scales to match the perceptual ratings from study 1a. Results of these two categorization tasks are presented in table 6 .

To categorize the tools as promotion or prevention oriented, we adopted the approach suggested by Higgins (2001) for the RFQ scale. First, we computed summated scales for PM and PV. Then, PV scores were subtracted from PM scores. As we collected the data about different tools from independent groups, all the calculations were performed with standardized scores. The value of the mean standardized scores presented in the table 6 illustrates the difference between PM and PV scores, where a positive sign indicates promotion focus and a negative sign indicates prevention focus. Finally, because in the categorization task in study 1a we had 3 categories (tool evaluated as promotion or prevention oriented or neutral), we split the difference between PM and PV scores into 3 parts, making the results from the two studies comparable. The predicted orientation of tools from study $1 \mathrm{a}$ is marked in italics under each tool in table 6. Chi-square tests indicate no significant differences in ratings for promotion, prevention and neutral evaluations of each tool between studies $1 \mathrm{a}$ and 4 . Consequently, those studies are one confirmation of the predictive validity of the developed scale.

Place Table 6 about here

\section{Study 5: Nomological Validity}

Nomological validity is the extent to which a measure fits into a network of expected relationships called a "nomological network" (Nunnally and Bernstein 1994). To test whether the developed measures for PM and PV correspond to the regulatory focus theory network 
requires that the tools defined as predominately PM or PV by these measures fit with RF predictions when matched with individual goal orientation. RF predicts that when people with a promotion or prevention goal orientation are given a strategy of goal pursuit that matches that orientation, they 'feel right'(Cesario et al. 2004), are more engaged with the activity (Higgins et al. 1994), and place greater value on the outcome of the goal pursuit (Pham and Chang 2010), thus are willing to invest more effort in goal pursuit. Consequently, for nomological validity of the derived PM-PV measures we create the RF conditions by matching individual goal orientation with a tool for health management of the same orientation (as predicted by the PM-PV measure). Thus, we aimed to test the following hypotheses:

H1a. Match (fit) of individual orientation with tool predicted orientation will lead to stronger 'feeling right' about using the tool than when there is a mismatch (non-fit) between orientation and tool.

H1b. Match (fit) of individual orientation with tool predicted orientation will lead to greater effort intentions to put towards the use of the tool than when there is a mismatch (non-fit) between orientation and tool.

Data Collection. A 2 (promotion, prevention) by 2 (promotion tool, prevention tool) between groups experimental design was used with data gathered through Amazon Mechanical Turk to test the hypotheses ( $n=86$; US males $72 \%$ /females $28 \%$ ). There were no systematic differences by demographics between the experimental groups.

Independent Variables. First, each participant answered the RFQ (Higgins et al. 2001) followed by some demographic questions, thus providing some separation of individual RFQ questions from the stimuli. Next, by random assignment, participants viewed descriptions and 
photographs of one of the 2 tools highest on promotion scores (application for running and activity wristband) or 2 tools highest on prevention scores (body scanner and health information application), then evaluated that tool on the PM-PV scale questions. Forster et al. (1998) and Daryanto et al. (2010) also use RFQ before the stimuli to help prevent contamination of RFQ based categorization with the information provided in the stimuli.

Dependent Variables. The remaining part of questionnaire measured the outcome variables: effort and 'feeling right'. Effort is an indication of potential engagement with the tool (Pham and Chang 2010). Two questions evaluated effort: 'How much effort would you be prepared to spend on searching, accessing and downloading the tool?' and 'How much effort would you be prepared to spend to put into learning how to use the tool?' (1-very little, 9great deal) ( $\alpha=.90)$. To break between the effort and 'feeling right' measures, further demographic questions and a repeated tool description appeared next, before the 'feeling right' items. An adapted 'feeling right' measure from Camacho et al. (2003) consisted of two items: 'It feels right to use this tool for meeting my health needs' (1- strongly disagree, 9 strongly agree) and 'Using this tool fits with my healthcare needs/health habits' (1- not at all, 9-extremely well) $(\alpha=.85)$

Covariates. Since Higgins et al. (2003) consider perceived effectiveness and ease of use of the tool as extraneous variables, we included those variables in the questionnaire in order to use as controls for any effects on effort. The items were: 'How effective do you think using this tool would be to meet your health needs?' (1-not at all effective, 9-extremely effective), 'Please rate the extent to which using this tool could improve your future health?' (1-not at all, 9-very much) ( $\alpha=.90)$, and 'How easy would it be for you to use this tool?' (1very difficult, 9-very easy). Additionally, we included an assessment of positive mood because the effects of fit concern specifically 'feeling right', which is distinct from classic hedonic pleasure (Cesario and Higgins 2008). It was expected that the effect of 'feeling right' 
will be independent of positive mood of participants. The mood measure included a 9 point semantic differential scale with the following items: good-bad, happy-sad, relaxed-tense, content -discontent, positive -negative, and cheerful-miserable $(\alpha=.90)$.

Results. Using standardized scores, manipulation check questions on grouped PM-PV scores confirmed that people indeed have perceptions of tools as having either a promotion or prevention nature. Those assigned a tool previously judged to be promotion-orientated, rated the tools higher on PM scores $(\mathrm{M}=.49, \mathrm{SD}=.57)$ than on $\mathrm{PV}$ scores $(\mathrm{M}=-.36, \mathrm{SD}=.98, \mathrm{df}=42$, $\mathrm{t}=5.51, \mathrm{p}<.001$ ), while those who were assigned a tool previously judged to be preventionorientated rated the tools higher on PV scores $(\mathrm{M}=.33, \mathrm{SD}=.99)$ than on PM scores $(\mathrm{M}=-.27$, $\mathrm{SD}=1.14, \mathrm{df}=43, \mathrm{t}=6.49, \mathrm{p}<.001)$. Those results of paired t-tests provide further support for the predictive validity of PM-PV scales.

Supporting hypothesis 1a, an assessment of perceptions of 'feeling right' for match and non-match manipulations found, as expected, (using standardized scores) higher perceptions of 'feeling right' $(\mathrm{M}=.33, \mathrm{SD} .74)$ in the case of a match (fit) between individual orientation and tool orientation, than in a mismatch (non-fit) situation ( $\mathrm{M}=-.06, \mathrm{SD}=.97$, $\mathrm{F}=4.182$, $\mathrm{p}=.04$ ). As desired, controlling for positive mood does not affect this relationship. Supporting hypothesis $1 \mathrm{~b}$, analysis of effort under match and mismatch conditions showed that effort under match(fit) conditions $(\mathrm{M}=.38, \mathrm{SD}=.76)$ is significantly higher than effort in mismatch (non-fit) conditions $(\mathrm{M}=-.08, \mathrm{SD}=1.01, \mathrm{~F}(1,84)=5.710, \mathrm{p}=.02)$ Controlling for perceived effectiveness and ease of use associated with a given tool does not change the nature of the interaction effect but does change the significance of the interaction effect, although leaving it within the acceptable boundaries $(F(1,82)=3.529, p=.06)$.

The overall results confirm our hypotheses that fit between individual orientation and tool orientation will result in higher intended effort and 'feeling right' than non-fit. Additionally, this possibility of inducing fit or non-fit with promotion or prevention tools 
indicates that the developed scales have the ability to correctly differentiate between promotion and prevention tools and strongly suggests nomological validity.

\section{Study 6: Final Validation}

\section{Data Collection}

To confirm the characteristics of the developed scale, we conducted another large study ( $n=242$, US adults male 57\%; female 43\%; age range 18 - 79 years (mean 32 years) with a sample recruited from the AMT online panel. Random assignment was to 6 groups, where each group viewed one tool from 2 promotion (application for running; activity wristband), 2 prevention (body scanner; health information application) and 2 neutral (weight management application and health records). There were no systematic differences by gender or age. Answers to the PM-PV items were then grouped as a nested file for CFA analysis.

\section{Validation of Measurement Properties}

The CFA results confirmed that the two factor solution (6 PM items and 5 PV items) provides a good fit. Again, the two-factor solution with 11 items $\left(\chi^{2}=81.012 \mathrm{df}=43\left(\chi^{2} / \mathrm{df}=1.88\right)\right.$, $\mathrm{CFI}=.98, \mathrm{IFI}=.98, \mathrm{GFI}=.94$ and $\mathrm{RMSEA}=.06$, PCLOSE $=.185$ ) provides a better solution than the one factor solution. All items loaded highly on respective factors confirming convergent validity of the scales. As presented in table 4, it is clear that the AVEs for each construct exceeded .50. Finally, calculation of construct reliability and Cronbach’s Alpha were within acceptable limits, ranging from .88 to .93 (see table 5).

\section{Discriminant Validity}

For discriminant validity, since approach strategies are preferred by promotion and avoidance strategies by prevention orientation, we expect that approach scores have a stronger positive relationship with promotion scores while avoidance scores have a stronger positive relationship with prevention scores. Higgins et al. (2001) use this approach in validating the RFQ scale, using Carver and White's (1994) Behavioral Approach System (BAS) and 
Behavioral Inhibition System (BIS) scales. We mainly followed this approach but, since the PM-PV scales relate to goals, not individual characteristics, we use scales of Approach and Avoidance developed by Elliot (1999), which are more appropriate to this situation.

Table 7 presents the results (alongside those for convergent validity for ease of comparison and presentation). In study 6, there were 6 tools altogether, 2 promotion, 2 prevention and 2 neutral. We use the scores from the 2 tools for promotion and 2 for prevention orientation to calculate the strength of the relationships. The relationships between PM-PV and Approach -Avoidance scores are as expected. PM scores have a stronger correlation with Approach scores $(\mathrm{r}=.46, \mathrm{p}<.01)$ than with Avoidance scores $(\mathrm{r}=.27, \mathrm{p}<$ $.01)$ and PV scores showed a stronger correlation with Avoidance $(\mathrm{r}=.48, \mathrm{p}<.01)$ than Approach $(\mathrm{r}=.27, \mathrm{p}<.01)$ scores.

As such, those different relationships examined within this data collection in studies 4 and 6 were found to be as expected, thus providing further evidence of construct validity.

Place Table 7 about here

\section{Social Desirability Bias}

Non-significant correlations of the PM-PV scales with a 10 item short form of the Social Desirability Scale (Strahan and Gerbasi, 1972) indicate that socially desirable responding did not endanger the validity of the developed measures (see table 7).

\section{Predictive Validity}

Following the procedures for predictive validity performed earlier on the data from studies 1a and 4 , we tested the predictive validity with the data from study 6 . The categorizations of 6 tools, followed by a Chi-square test indicates no significant differences in tool rating between results from study 6 and study 1a, thus further confirming the scales predictive validity. 


\section{DISCUSSION AND IMPLICATIONS}

In this paper we present the development and validation of a PM-PV scale, offering a parsimonious, two-dimensional scale. The assumption of this research is that development of this easily applicable scale will offer an effective and efficient tool for differentiating promotion- from prevention- oriented products or services within the healthcare context. This appears to be the case, a series of different studies has shown the measure to have a reliable ability to distinguish between perceived health tool orientation, plus satisfactory internal reliability, convergent and divergent validity. The applicability of the scale for both theory and practice are further discussed.

From theoretical point of view, it is very important that regulatory orientation can be transferred to products; these studies provide additional evidence that this is the case. The findings from these studies add an extra layer to consider when inducing and analyzing regulatory fit situations regarding use of products or services. Quite often studies simply match individual goal orientation with an appropriate message framing hoping for more participative or more valued outcomes (Cesario, Grant and Higgins 2004). However, current research suggests that reactions to the framing of promotional messages might interact with perceptions of product orientation and so result in inconsistent outcomes across studies. Also, we may expect reactions to different products to differ by the individual focus. In both these cases, the developed PR- PV scale can serve as means of classifying the perceived regulatory nature of those products. As such, assessment of interactions among different orientations of regulatory focus, product and message enables better understanding of RF effects.

Second, the scale can make a significant impact on practice, particularly in healthcare services. As Keckley and Coughlin (2012) emphasize, there is a recognizable consumerization of healthcare services. Hence to truly serve consumers designing customized healthcare practices (i.e., differentiation of promotion and prevention orientated tools) is a priority for 
healthcare practitioners, managers and policymakers. For healthcare professionals this knowledge can facilitate appropriate recommendations for medical treatments. For instance, one of the more innovative approaches in physicians' offices could be a test for individual goal orientation (Higgins et al. 2001), which could help physicians recognize what type of health management tool to use to match the individual motivation orientation of each patient. In the case of pharmaceutical companies, which often use different technologies to increase medical compliance (Reilly 2012), the differentiation of those technologies into promotion and prevention focused should make this task easier. Finally, health insurance providers, seeking the help of health technologies in providing most cost effective methods for health promotion and management (Keckley and Coughlin 2012), could also introduce customized technologies for individuals.

Another sector that could benefit from this research is amongst companies designing technologies for health management. Many of those innovations fail in application (Van Gemert-Pijnen et al. 2011), so an objective of those firms is to make those technologies more acceptable for different users. Using these research findings and building on RFT, those companies can differentiate design of tools on promotion and prevention characteristics that will appeal strongly to individual motivation orientations, and make the tools more acceptable to different groups of consumers.

Finally, this research should be of interest to policymakers in helping health policy translate into practice and benefit patients. One consideration could be patients’ needs for customized health practices, such as promotion or prevention oriented tools. Rather than building on 'one size fits all' rule, which is often ineffective and leads to a waste of resources, we believe that using the PM-PV scale to identify and match tools/products to user orientation can help in translating consumer-entered health policies into practice.

\section{LIMITATIONS AND FUTURE RESEARCH}


This study has certain limitations. First, locating the study in the healthcare context, whilst important in its own right, limits our understanding of promotion and prevention characteristics of products in different industries. Notwithstanding, the wording of the PM-PV scale can be adapted for different types of products and services outside the healthcare domain. For instance, recognition of promotion or prevention orientated education products or strategies appropriate for different pupils might prove useful in advancing student progression.

Additionally, although widely varied, the research was limited to a sample of 10 tools for healthcare management and therefore does not address the full complexity of interactions between chronic goal orientation and a more extensive range of tools. Further research is needed with different health management tools in order to identify a fuller range of different products with strong promotion and prevention nature and the effects on regulatory fit outcomes. We offer the building blocks to such future research by offering a functional mapping of different types of tools in terms of prevention and promotion orientation. In exploring the further interactions between tools and RF, future research can consider if different combinations (or packaging) of different tools could be matched to the individual.

Finally, there may also be boundary effects in respect to the strength of perceived RF orientation of the tools/platforms and how product characteristics are perceived in different situations, e.g., whether or not payment for use is required or in high involvement vs. in low involvement situations. Further study is also required on potential differences in consumer reactions for a greater range of (mis)matches of tool orientation and or induced goal orientation. How those different perceptions affect consumer decision making processes can advance current understanding of consumer behavior. 


\section{REFERENCES}

Aitken, Murray and Carolyn Gauntlett (2013), "Patient Apps for Improved Healthcare. From Novelty to Mainstream." Parsippany, NJ: IMS Institute for Healthcare Informatics (available at www.imshealth.com/deployedfiles/imshealth/Global/Content/Corporate /IMS\%20Health\%20Institute/Reports/Patient_Apps/IIHI_Patient_Apps_Report.pdf

Arrindell, Willem A., and Jan van der Ende (1985). “An empirical test of the utility of the observations to variables ratio in factor and components analysis,” Applied Psychological Measurement, 9(2), 165-78

Avnet, Tamar, and E. Tory Higgins (2006), “How Regulatory Fit Affects Value in Consumer Choices and Opinions,” Journal of Marketing Research, 43(1), 1-10.

Berinsky, Adam J., Gregory A. Huber, Gabriel S. Lenz (2012). “Evaluating Online Labor Markets for Experimental Research: Amazon.com's Mechanical Turk,” Political Analysis, 20(3), 351-368

Brocato, E. Deanne, Clay M. Voorhees, and Julie Baker (2012), "Understanding the Influence of Cues from Other Customers in the Service Experience: A Scale Development and Validation," Journal of Retailing, 88 (3), 384-98.

Camacho, Christopher. J., Higgins, E. Tory, and Luger Lindsay (2003), "Moral Value Transfer from Regulatory Fit: What Feels Right is Right and what Feels Wrong is Wrong," Journal of Personality and Social Psychology, 84(3), 498-510.

Carter, Michelle C., Victiria J. Burley, Camilla Nykjaer, and Janet E. Cade (2013), "Adherence to a Smartphone Application for Weight Loss Compared to Website and Paper Diary: Pilot Randomized Controlled Trial," Journal of Medical Internet Research, 15 (4), e32. 
Carver, Charles S. and Teri L. White (1994), "Behavioral Inhibition, Behavioral Activation, and Affective Responses to Impending Reward and Punishment: The Bis/Bas Scales," Journal of Personality \& Social Psychology, 67 (2), 319-33.

Cesario, Joseph, Heidi Grant, and E. Tory Higgins (2004), "Regulatory Fit and Persuasion: Transfer from "Feeling Right."," Journal of Personality and Social Psychology, 86 (3), 388-404.

Cesario, Joseph and E. Tory Higgins (2008), "Making Message Recipients "Feel Right”. How Nonverbal Cues Can Increase Persuasion.," Psychological Science, 19 (5), 415-20.

Cesario, Joseph, E. Tory Higgins, and Abigail A. Scholer (2008), "Regulatory Fit and Persuasion: Basic Principles and Remaining Questions," Social and Personality Psychology Compass, 2 (1), 444-63.

Churchill, Gilbert A., Jr. (1979), "A Paradigm for Developing Better Measures of Marketing Constructs," Journal of Marketing Research, 16 (1), 64-73.

Crowne, Douglas P. and David Marlowe (1960), "A New Scale of Social Desirability Independent of Psychopathology," Journal of Consulting Psychology, 24 (4), 349-54. Dabholkar, Pratibha. A., Thorpe, Dayle I., and Joseph O. Rentz (1995), "A Measure of Service Quality for Retail Stores: Scale Development and Validation". Journal of the Academy of Marketing Science, 24(1), 3-16.

Daryanto, Ahmad, Ko de Ruyter, Martin Wetzels, and Paul Patterson (2010), "Service Firms and Customer Loyalty Programs: A Regulatory Fit Perspective of Reward Preferences in a Health Club Setting," Journal of the Academy of Marketing Science,38(5),604-16.

DeVellis, Robert F. (2011). Scale Development: Theory and Applications (Applied Social Research Methods). SAGE Publications. Kindle Edition. 
Fornell, Claes and David F. Larcker (1981), "Evaluating Structural Equation Models with Unobservable Variables and Measurement Error," Journal of Marketing Research, 18 (1), 39-50.

Fox, Susannah, Maeve Duggan, Lee Rainie, and Kristen Purcell (2013), "The Diagnosis Difference. A Portrait of the 45\% of U.S. Adults Living with Chronic Health Conditions.," Pew Research Center (available at http://www.pewinternet.org/files/oldmedia//Files/Reports/2013/PewResearch_DiagnosisDifference.pdf)

Gerbing, David W. and James C. Anderson (1988), "An Updated Paradigm for Scale

Development Incorporating Unidimensionality and Its Assessment," Journal of Marketing Research, 25 (2), 186-92.

Hair, Joseph F., William C. Black, Barry J. Babin, and Anderson Rolph E. (2008), Multivariate Data Analysis. A Global Perspective: Pearson Education.

Halvorson, Heidi and E. Tory Higgins (2013), "Do You Play to Win - or Not to Lose?," in Harvard Business Review Online, March 2013 (available at http://hbr.org/2013/03/doyou-play-to-win-or-to-not-lose/ar/1)

Hardesty, David M. and William O. Bearden (2004), "The Use of Expert Judges in Scale Development: Implications for Improving Face Validity of Measures of Unobservable Constructs," Journal of Business Research, 57 (2), 98-107.

Higgins, E. Tory. (1987), "Self-Discrepancy: A Theory Relating Self and Affect," Psychology Review, 94 (3), 319-40.

------ (2014), Beyond Pleasure and Pain. How Motivation Works. Oxford: Oxford University Press.

------ (1998), "Promotion and Prevention: Regulatory Focus as a Motivational Principle," in Advances in Experimental Social Psychology, P. Zanna Mark, ed. Vol. Volume 30: Academic Press. 
------ (2006), "Value from Hedonic Experience and Engagement," Psychological Review, 113 (3), 439-60.

Higgins, E. Tory, Ronald S. Friedman, Robert E. Harlow, Lorraine Chen Idson, Ozlem N. Ayduk, and Amy Taylor (2001), "Achievement Orientations from Subjective Histories of Success: Promotion Pride Versus Prevention Pride," European Journal of Social Psychology, 31 (1), 3-23.

Higgins, E. Tory, Christopher J. R. Roney, Ellen Crowe, and Charles Hymes (1994), "Ideal Versus Ought Predilections for Approach and Avoidance: Distinct Self-Regulatory Systems. ," 66 (2), 276-86.

Hoffmann, Stefan, Robert Mai, and Maria Smirnova (2011), "Development and Validation of a Cross-Nationally Stable Scale of Consumer Animosity," Journal of Marketing Theory \& Practice, 19 (2), 235-52.

Hortensius, Johanna, Marijke Kars, Willem Wierenga, Nanne Kleefstra, Henk Bilo, and Jaap van der Bijl (2012), "Perspectives of Patients with Type 1 or Insulin-Treated Type 2 Diabetes on Self-Monitoring of Blood Glucose: A Qualitative Study," Bmc Public Health, 12 (1), 167.

Keckley, Paul H. and Sheryl Coughlin (2012), "Deloitte 2012 Survey of U.S. Health Care Consumers: The Performance of the Health Care System and Health Care Reform." Washington D.C.: Deloitte Center for Health Solutions (available at file:///D:/Users/mzyxjmn3/Downloads/Deloitte+-+Health+Care+Reform++ Center+Stage+2012.pdf)

Keeling, Debbie Isobel, Ahmad Daryanto, Ko de Ruyter, and Martin Wetzels (2013), "Take It or Leave It: Using Regulatory Fit Theory to Understand Reward Redemption in Channel Reward Programs," Industrial Marketing Management 42(8) 1345-56. 
Ku, Hsuan-Hsuan, Chien-Chih Kuo, and Tzu-Wei Kuo (2012), "The Effect of Scarcity on the Purchase Intentions of Prevention and Promotion Motivated Consumers," Psychology and Marketing, 29 (8), 541-48.

MacCallum, Robert C., Keith Widaman F., Shaobo Zhang, and Sehee Hong (1999), "Sample Size in Factor Analysis". Psychological Methods, 4(1), 84-99.

Malhotra, Naresh K. (1981), "A Scale to Measure Self-Concepts, Person Concepts, and Product Concepts," Journal of Marketing Research, 18 (4), 456-64.

Micu, Camelia C. and Tilottama G. Chowdhury (2010), "The Effect of Message's Regulatory Focus and Product Type on Persuasion," Journal of Marketing Theory \& Practice, 18 (2), 181-90.

Molden, Daniel C., Angela Lee, and E. Tory Higgins (2008), "Motivations for Promotion and Prevention". New York: Guilford Press.

Nunnally, Jum C. and Ira H. Bernstein (1994), "Psychometric Theory". Hillsdale, NJ: McGraw-Hill.

Park, Sungmee and Jayaraman, Sundaresan (2003), "Enhancing the Quality of Life through Technology: The Role of Personalized Wearable Intelligent Information Infrastructure," IEEE Engineering in Medicine and Biology, 23 (2), 41-48.

Pham, Michel Tuan and Hannah H. Chang (2010), "Regulatory Focus, Regulatory Fit, and the Search and Consideration of Choice Alternatives," Journal of Consumer Research, 37 (4), 626-40.

Ramsey, Rosemary P. and Dawn R. Deeter-Schmelz (2008), "An Assessment of the Psychometric Properties of the Style-of-Processing (Sop) Scale: How Do We Measure Individuals' Verbal/Visual Information-Processing Preferences?," Journal of Marketing Theory \& Practice, 16 (1), 41-55. 
Reilly, Michael (2012), "The Case for Investment in Mhealth," London (available at http://www.blears.com/images/AIR.pdf).

Ruder Finn (2013), "mHealth Report," London (available at http://www.ruderfinn.com/pdf /Ruder\%20Finn\%20US\%20mHealth\%20report\%20FINAL.pdf)

Spiegel, Scott, Heidi Grant-Pillow, and Tory E. Higgins (2004), "How regulatory fit enhances motivational strength during goal pursuit," European Journal of Social Psychology, 34 (1), 39-54.

Strahan, Robert and Kathleen C. Gerbasi (1972), "Short, Homogeneous Versions of the Marlow-Crowne Social Desirability Scale,"Journal of Clinical Psychology, 28(2), 191-93.

Summerville, Amy and Neal J. Roese (2008), "Self-Report Measures of Individual Differences in Regulatory Focus: A Cautionary Note," Journal of Research in Personality, 42 (1), 247-54.

Van Gemert-Pijnen, E. W. C. Julia, Nicol Nijland, Maarten van Limburg, C. Hans Ossebaard, M. Saskia Kelders, Gunther Eysenbach, and R. Erwin Seydel (2011), "A Holistic Framework to Improve the Uptake and Impact of Ehealth Technologies," Journal of Medical Internet Research 13 (4), e111.

Voss, Kevin E., Eric R. Spangenberg, and Bianca Grohmann (2003), "Measuring the Hedonic and Utilitarian Dimensions of Consumer Attitude," Journal of Marketing Research, 40 (3), 310-20.

Zaichkowsky, Judith L. (1985), "Measuring the Involvement Construct," Journal of Consumer Research, 12 (3), 341-52.

Zhou, Rongrong and Michel Tuan Pham (2004), "Promotion and Prevention across Mental Accounts: When Financial Products Dictate Consumers’ Investment Goals," Journal of Consumer Research, 31 (1), 125-35. 
Table 1

Theoretical Foundations for Scale Development

\begin{tabular}{|l|l|}
\hline \multicolumn{1}{|c|}{$\begin{array}{c}\text { Individual characteristics from } \\
\text { literature review }\end{array}$} & \multicolumn{1}{c|}{$\begin{array}{c}\text { Proposed tool characteristics for } \\
\text { item construction }\end{array}$} \\
\hline Promotion \\
\hline $\begin{array}{l}\text { Preference for approach strategies of } \\
\text { goal pursuit }\end{array}$ & $\begin{array}{l}\text { Perceived as meeting needs of } \\
\text { accomplishment (ideals) }\end{array}$ \\
\hline $\begin{array}{l}\text { Focus on presence/absence of } \\
\text { positive outcomes (gains) }\end{array}$ & $\begin{array}{l}\text { Perceived as helping to achieve } \\
\text { positive outcomes (gains) }\end{array}$ \\
\hline $\begin{array}{l}\text { Search for emotional reactions from } \\
\text { gains (happiness, excitement) }\end{array}$ & $\begin{array}{l}\text { Perceived as helping gain positive } \\
\text { emotional satisfaction }\end{array}$ \\
\hline \multicolumn{2}{|c|}{ Prevention } \\
\hline $\begin{array}{l}\text { Needs for safety (ought) } \\
\text { Preference for avoidance strategies } \\
\text { of goal pursuit }\end{array}$ & $\begin{array}{l}\text { Perceived as meeting needs for } \\
\text { safety (oughts) }\end{array}$ \\
\hline $\begin{array}{l}\text { Focus on presence/absence of } \\
\text { negative outcomes (losses) } \\
\text { goal pursuit }\end{array}$ \\
\hline $\begin{array}{l}\text { Avoidance of emotional reactions } \\
\text { from losses (disappointment, anger) }\end{array}$ & $\begin{array}{l}\text { Perceived as helping to avoid } \\
\text { negative outcomes (losses) }\end{array}$ \\
\hline $\begin{array}{l}\text { Perceived as helping avoid negative } \\
\text { emotions, e.g., disappointment or } \\
\text { irritation }\end{array}$ \\
\hline $\begin{array}{l}\text { Sources: Higgins (1998); Higgins et al. (2001), Molden, Lee and Higgins (2008), } \\
\text { Higgins et al. (2003), Cesario, Higgins, and Scholer (2008) }\end{array}$ \\
\hline
\end{tabular}


Figure 1

Scale Development Process

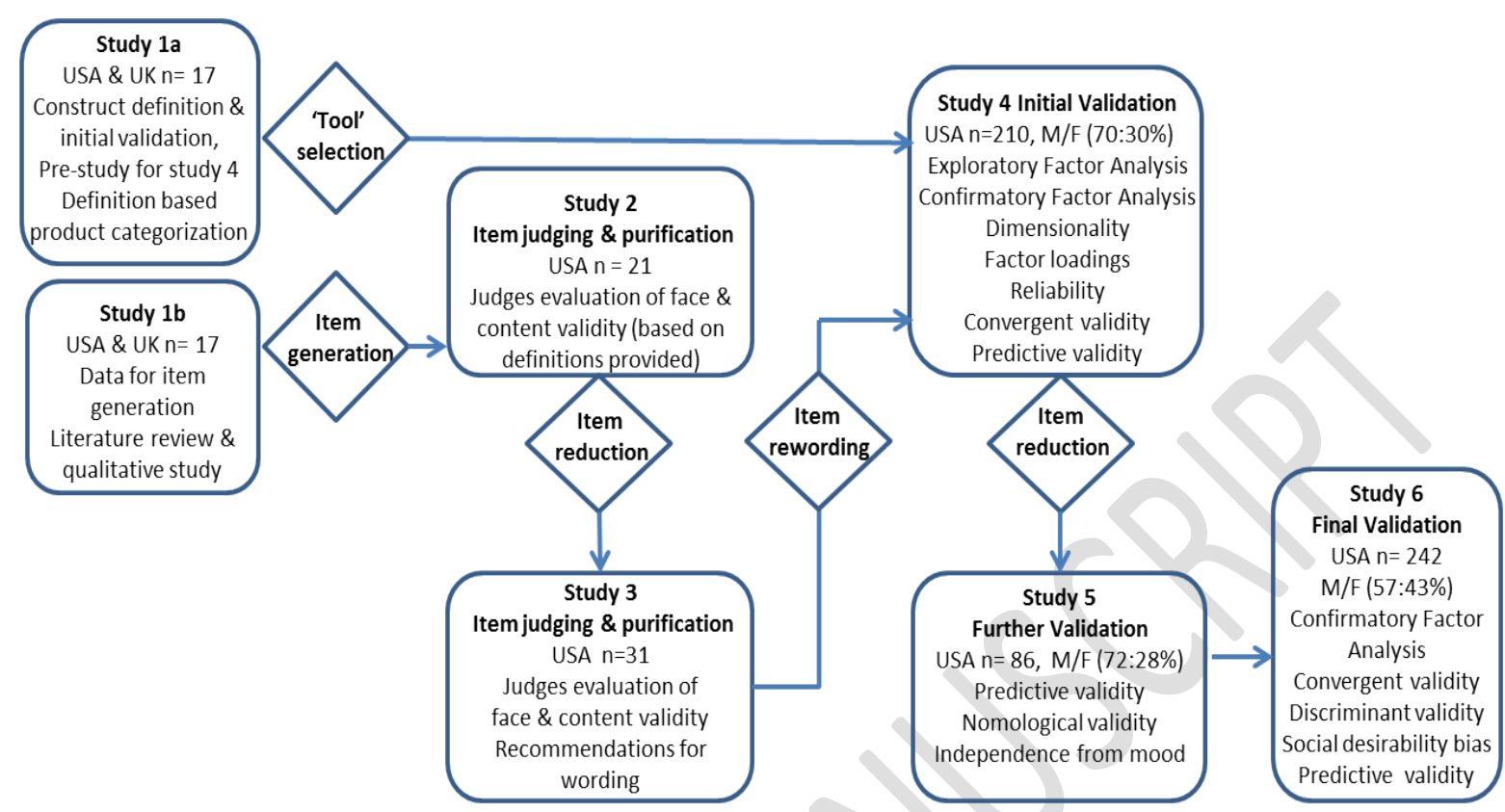


Table 2

Promotion and Prevention Focus Definitions

\section{Promotion focus}

Promotion-focused individuals see their goals as leading to gains or advancement. They concentrate on the rewards (positive outcome) from their goal pursuits. They play to win and strive to realise their ideals and aspirations. During goal pursuit they address their needs of growth and advancement: approach their goals with eagerness and are sensitive to gains and non gains. Such people feel comfortable taking chances, they like to work quickly and think creatively. Promotion-focused individuals are keen on change in their lives as long as this change is seen in terms of gains.

\section{Prevention focus}

Prevention-focused individuals see their goals as responsibilities and they concentrate on being safe (focus on avoiding negative outcomes) during goal pursuit. They tend to worry about potential losses in cases when they are underperforming or are not careful enough. Striving to fulfil their duties and obligations, during goal pursuit they address their needs for safety and security and so approach their goals with vigilance and are sensitive to losses and non losses. Prevention focused individuals play to not lose, striving to maintain the status quo and tend to be risk-averse.

\section{Prevention and Promotion Focused Tools}

Promotion/prevention orientated health products are products meeting user needs for accomplishment/safety relative to their health. Use of a promotion orientated health tool is associated with approaching gains (happiness) resulting from successful goal pursuit relative to a user's health (e.g. health improvement). Use of a prevention orientated health tool is associated with avoiding losses (disappointment) that could result from failure in goal pursuit relative to a user's health (e.g., health deterioration).

Sources: Halvorson and Higgins (2013), Pham and Chung (2010) 
Table 3

Principal Component Analysis on the Promotion-Prevention Items

\begin{tabular}{|c|c|c|}
\hline \multicolumn{3}{|l|}{ Component loading for two-factor solution (Oblique) } \\
\hline \multirow{2}{*}{ Promotion and prevention items } & \multicolumn{2}{|c|}{ Component } \\
\hline & $\mathrm{I}$ & II \\
\hline \multicolumn{3}{|l|}{ Promotion (PM) items } \\
\hline 1. Improve their health & .661 & \\
\hline 2. Fulfill needs for their ideal health & .724 & \\
\hline 3. See themselves as striving to fulfill their health plans and goals & .858 & \\
\hline 4. Focus on achieving desired health outcomes & .827 & 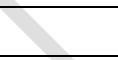 \\
\hline 5. Be successful in attaining future health goals & .871 & \\
\hline 6. Achieve hopes and aspirations for their health & .858 & \\
\hline \multicolumn{3}{|l|}{ Prevention $(\mathrm{PV})$ items } \\
\hline 1. Take precautions to lead a safe and healthy life & 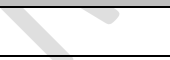 & .671 \\
\hline 2. Reduce health concerns & ) & .630 \\
\hline 3. Focus on protecting themselves from unwanted health outcomes & & .793 \\
\hline 4. Safeguard against mistakes that might impact their health & & .828 \\
\hline 5. Prevent health failures & & .800 \\
\hline 6. Stop unwanted health crises & & .849 \\
\hline$+\sqrt{n}$ & & \\
\hline \multicolumn{3}{|l|}{ Removed items (from the 17 items) } \\
\hline \multicolumn{3}{|l|}{ Feel happy because they have done their best to improve their health } \\
\hline \multicolumn{3}{|l|}{ Find excitement in improving their well being } \\
\hline \multicolumn{3}{|l|}{ Avoid feeling angry about previous disregard for health } \\
\hline \multicolumn{3}{|l|}{ Avoid disappointment with their health } \\
\hline Take responsibility for their own health & & \\
\hline
\end{tabular}


Table 4

Scale Items, Descriptive Statistics and Factor Loadings

\begin{tabular}{|c|c|c|c|c|c|c|}
\hline \multirow{2}{*}{ Factor item } & \multicolumn{3}{|c|}{ Study 4} & \multicolumn{3}{|c|}{ Study 6} \\
\hline & Mean & SD & $\lambda$ & Mean & SD & $\lambda$ \\
\hline \multicolumn{7}{|l|}{ Promotion (PM) items } \\
\hline 1. Improve their health & 6.90 & 1.66 & .73 & 7.13 & 1.8 & .76 \\
\hline 2. Fulfill needs for their ideal health & 6.53 & 1.66 & .79 & 6.78 & 1.8 & .83 \\
\hline $\begin{array}{l}\text { 3. See themselves as striving to fulfill their } \\
\text { health plans and goals }\end{array}$ & 7.19 & 1.56 & .75 & 7.17 & 1.87 & .86 \\
\hline $\begin{array}{l}\text { 4. Focus on achieving desired health } \\
\text { outcomes }\end{array}$ & 7.13 & 1.63 & .77 & 7.26 & 1.75 & .88 \\
\hline $\begin{array}{l}\text { 5. Be successful in attaining future health } \\
\text { goals }\end{array}$ & 7.00 & 1.55 & .84 & 7.07 & 1.7 & .84 \\
\hline $\begin{array}{l}\text { 6. Achieve hopes and aspirations for their } \\
\text { health }\end{array}$ & 6.90 & 1.63 & .79 & 6.93 & 1.82 & .83 \\
\hline \multicolumn{7}{|l|}{ Prevention (PV) items } \\
\hline $\begin{array}{l}\text { 1. Take precautions to lead a safe and } \\
\text { healthy life }\end{array}$ & 6.75 & 1.80 & .79 & 6.65 & 1.9 & .79 \\
\hline $\begin{array}{l}\text { 2. Focus on protecting themselves from } \\
\text { unwanted health outcomes }\end{array}$ & 6.30 & 1.87 & .79 & 6.19 & 2.14 & .82 \\
\hline $\begin{array}{l}\text { 3. Safeguard against mistakes that might } \\
\text { impact their health }\end{array}$ & 6.14 & 1.91 & .71 & 5.97 & 2.26 & .81 \\
\hline 4. Prevent health failures & 6.00 & 2.01 & .76 & 5.76 & 2.21 & .72 \\
\hline 5. Stop unwanted health crises & 5.70 & 2.05 & .71 & 5.60 & 2.35 & .68 \\
\hline
\end{tabular}

SD-standard deviation, $\lambda$-standardized lambda loading. 
Table 5

Results of Measurement Model Assessment and Scale Statistics

\begin{tabular}{|c|c|c|c|c|}
\hline \multirow{2}{*}{ Construct } & \multirow{2}{*}{ CR } & \multirow{2}{*}{ AVE } & \multicolumn{2}{|c|}{ Correlations } \\
\hline & & & 1 & 2 \\
\hline \multicolumn{5}{|l|}{ Study 4} \\
\hline 1. Promotion & .90 & .60 & & .62 \\
\hline 2. Prevention & .87 & .57 & .62 & \\
\hline \multicolumn{5}{|l|}{ Study 6} \\
\hline 1. Promotion & .93 & .70 & & .65 \\
\hline 2. Prevention & .88 & .59 & .65 & \\
\hline
\end{tabular}


Table 6

Predictive Validity in Product Categorizations

\begin{tabular}{|c|c|c|c|c|c|c|c|c|}
\hline \multirow[b]{2}{*}{ Tool } & \multicolumn{4}{|c|}{$\begin{array}{c}\text { Study } 4 \\
\text { Scale based classification }\end{array}$} & \multicolumn{4}{|c|}{$\begin{array}{c}\text { Study } 1 \mathrm{a} \\
\text { Definition based categorization } \\
\end{array}$} \\
\hline & $\begin{array}{l}\text { Mean (Z) } \\
\text { (sd) }\end{array}$ & PM & PV & NT & PM & PV & NT & Chi sq \\
\hline $\begin{array}{l}\text { Weight management } \\
\text { application } \\
\text { Promotion-neutral** }\end{array}$ & $.06(.77)$ & $38 \%$ & $19 \%$ & $43 \%$ & $59 \%$ & $12 \%$ & $29 \%$ & 2.31, ns \\
\hline $\begin{array}{l}\text { Activity wristband } \\
\text { Promotion } * / * *\end{array}$ & $.68(.85)$ & $62 \%$ & $14 \%$ & $24 \%$ & $86 \%$ & $7 \%$ & $7 \%$ & $2.4, \mathrm{~ns}$ \\
\hline $\begin{array}{l}\text { Body scanner } \\
\text { Prevention */** }\end{array}$ & $-.46(.58)$ & $5 \%$ & $67 \%$ & $29 \%$ & $7 \%$ & $79 \%$ & $14 \%$ & $1.00, \mathrm{~ns}$ \\
\hline $\begin{array}{l}\text { Health information } \\
\text { application } \\
\text { Prevention*/** }\end{array}$ & $-.64(.62)$ & $9 \%$ & $68 \%$ & $23 \%$ & $18 \%$ & $71 \%$ & $12 \%$ & $1.20, \mathrm{~ns}$ \\
\hline $\begin{array}{l}\text { Application for running } \\
\text { Promotion*/** }\end{array}$ & $1.05(1.22)$ & $86 \%$ & $5 \%$ & $9 \%$ & $71 \%$ & $6 \%$ & $24 \%$ & 1.80, ns \\
\hline $\begin{array}{l}\text { Health records ** } \\
\text { Prevention-neutral }\end{array}$ & $-.35(.59)$ & $14 \%$ & $33 \%$ & $52 \%$ & $12 \%$ & $53 \%$ & $35 \%$ & 1.92, ns \\
\hline $\begin{array}{l}\text { Working out application } \\
\text { Promotion }\end{array}$ & .55 (.75) & $55 \%$ & $0 \%$ & $45 \%$ & $64 \%$ & $7 \%$ & $29 \%$ & 1.96, ns \\
\hline $\begin{array}{l}\text { Medical reference } \\
\text { application } \\
\text { Prevention-neutral }\end{array}$ & $-.30(.99)$ & $24 \%$ & $38 \%$ & $38 \%$ & $14 \%$ & $36 \%$ & $50 \%$ & $0.67, \mathrm{~ns}$ \\
\hline $\begin{array}{l}\text { Tool for health support } \\
\text { Prevention }\end{array}$ & $-.37(.67)$ & $21 \%$ & $42 \%$ & $37 \%$ & $14 \%$ & $64 \%$ & $21 \%$ & 1.61, ns \\
\hline $\begin{array}{l}\text { Online community for } \\
\text { patient support } \\
\text { Prevention-neutral }\end{array}$ & $-.32(.63)$ & $15 \%$ & $49 \%$ & $36 \%$ & $21 \%$ & $36 \%$ & $43 \%$ & $1.04, \mathrm{~ns}$ \\
\hline $\begin{array}{l}\text { PM -Promotion, PV-Pre } \\
* \text { indicates the tools used } \\
* * \text { indicates the tools use }\end{array}$ & $\begin{array}{l}\text { ion, NT-N } \\
\text { tudy } 5 \\
\text { study } 6\end{array}$ & & & & & & & \\
\hline
\end{tabular}


Table 7

Convergent and discriminant validity of developed scales

\begin{tabular}{|c|c|c|c|c|c|}
\hline \multicolumn{3}{|c|}{$\begin{array}{l}\text { Study 4: Convergent validity: } \\
\text { Correlation coefficients: } \\
3 \text { promotion, } 3 \text { prevention tools, } n=127\end{array}$} & \multicolumn{3}{|c|}{$\begin{array}{l}\text { Study 6: Discriminant Validity } \\
\text { Correlation coefficients: } \\
2 \text { promotion, } 2 \text { prevention tools, } n=161\end{array}$} \\
\hline & Promotion & Prevention & & Promotion & Prevention \\
\hline \multirow{2}{*}{ Effectiveness } & $.57 * *$ & $.52 * *$ & Approach & $.46^{* *}$ & $.27^{* *}$ \\
\hline & & & Avoidance & $.20^{* *}$ & $.48^{* *}$ \\
\hline & & & & & \\
\hline & & & Social desirability & -.05 & -.08 \\
\hline$* \mathrm{p}<.01$ & & & & & 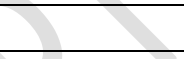 \\
\hline
\end{tabular}




\section{APPENDIX \\ Tool Description}

\begin{tabular}{|c|c|}
\hline Tool Type & Description \\
\hline $\begin{array}{l}\text { Weight management } \\
\text { application }\end{array}$ & $\begin{array}{l}\text { This is an application for your mobile phone (also available on a website) that can help } \\
\text { you manage your weight. It has a calorie counter, the food database of over } 1.2 \text { million } \\
\text { foods, and food and exercise entry. Thus, you can record what you eat and how you } \\
\text { exercise; you can set up nutritional goals and monitor how close/far you are from } \\
\text { reaching those goals. Finally, you can share all that with your friends. }\end{array}$ \\
\hline \multicolumn{2}{|c|}{$\begin{array}{l}\text { Source: MyFitnessPal, http://www.myfitnesspal.com, } \\
\text { https://play.google.com/store/apps/details?id=com.myfitnesspal.android, accessed May } 2013\end{array}$} \\
\hline Activity wristband & $\begin{array}{l}\text { It is a wristband which is connected to a mobile application and your online account. } \\
\text { This tool measures your everyday activity. It notes calories burned, steps taken and more. } \\
\text { It is also a watch. The band records running, walking, dancing, basketball and dozens of } \\
\text { everyday activities. You can decide how active you want to be by setting a daily goal. } \\
\text { Then, you can share your experiences with your friends and family. }\end{array}$ \\
\hline \multicolumn{2}{|c|}{$\begin{array}{l}\text { Source: Fitbit Flex, http://www.fitbit.com/uk/flex, } \\
\text { https://play.google.com/store/apps/details?id=com.fitbit.FitbitMobile, accessed May } 2013\end{array}$} \\
\hline Body scanner & $\begin{array}{l}\text { This is a scanning device that can grab your vitals, and then beam them to a Smartphone. } \\
\text { It is a small object that can measure your temperature, heart rate, oximetry (blood } \\
\text { oxygenation), run an electrocardiogram, gauge heart rate variability, clock pulse wave } \\
\text { transit time (related to blood pressure), perform a urine analysis and calculate a metric } \\
\text { the scanner refers to as 'stress'. To get these readings, urine analysis notwithstanding, } \\
\text { you need to hold the scanner against your forehead for a few seconds. Overall, this is a } \\
\text { scanner with different sensors that allows you conduct physical exams- in a snap. }\end{array}$ \\
\hline \multicolumn{2}{|c|}{$\begin{array}{l}\text { Source: Scandau Scout, https://www.scanadu.com/scout, } \\
\text { http://www.wired.co.uk/news/archive/2013-05/22/scanadu-scout-indiegogo, accessed May } 2013\end{array}$} \\
\hline $\begin{array}{l}\text { Health information } \\
\text { application }\end{array}$ & $\begin{array}{l}\text { This is a mobile application (also available through a website) that helps you to answer } \\
\text { health related questions. The tool describes thousands of medical symptoms, diseases, } \\
\text { conditions, procedures, medications and drugs and can help you find the nearest hospital, } \\
\text { emergency room, urgent care, retail clinic, pharmacy, physician, doctor, imaging center, } \\
\text { mental health clinic, substance abuse clinic, and community health center. With this } \\
\text { application you can make an appointment, check in for appointment, store a history of } \\
\text { your medical visits and view it all in your Personal Health Record. }\end{array}$ \\
\hline \multicolumn{2}{|c|}{$\begin{array}{l}\text { Source:iTriage, https://www.itriagehealth.com, , } \\
\text { https://play.google.com/store/apps/details?id=com.healthagen.iTriage, accessed May } 2013\end{array}$} \\
\hline $\begin{array}{l}\text { Application for } \\
\text { running }\end{array}$ & $\begin{array}{l}\text { This is a mobile application (also available through a website) that maps your runs. The } \\
\text { app records distance, pace, time and calories burnt with GPS, giving you audio feedback } \\
\text { as you run. All you need to do is to carry your phone with you when you run. Then, you } \\
\text { can automatically upload your results on an associated website to see your runs, } \\
\text { including your route and elevation. Also, you can share your running experiences with } \\
\text { your friends. }\end{array}$ \\
\hline \multicolumn{2}{|c|}{$\begin{array}{l}\text { Source:Nike+Running, https://nike.com, https://play.google.com/store/apps/details?id=com.nike.plusgps, } \\
\text { accessed May } 2013\end{array}$} \\
\hline Health records & $\begin{array}{l}\text { Personal Health Record (PHR) is a web based platform (also available as a mobile } \\
\text { application) for collection and management of personal health information. Health } \\
\text { information can be stored and shared, depending on your needs. This tool may store a } \\
\text { range of data, including demographics and personal data, such as age and weight, } \\
\text { medical history, medication and allergies, etc. }\end{array}$ \\
\hline \multicolumn{2}{|c|}{ Source: HealthVault, https://www.healthvault.com/gb/en, accessed May 2013} \\
\hline $\begin{array}{l}\text { Working out } \\
\text { application }\end{array}$ & $\begin{array}{l}\text { This is a mobile application with a } 5 \text { to } 10 \text { minute daily abdominal (ab) routine for men } \\
\text { and women that steps you through ten of the ab-sculpting exercises. These exercises, } \\
\text { demonstrated by a certified personal trainer, target all major abdominal muscles. The } \\
\text { routine's interface, complete with video and timer, allows you to easily follow along each } \\
\text { exercise. }\end{array}$ \\
\hline \multicolumn{2}{|c|}{$\begin{array}{l}\text { Source:DailyAb workout, https://play.google.com/store/apps/details?id=com.tinymission.dailyabworkoutfree1, } \\
\text { accessed May } 2013\end{array}$} \\
\hline Medical reference & oped to provide a quick look at the up-to date information on the \\
\hline
\end{tabular}




\begin{tabular}{|l|l|}
\hline application & $\begin{array}{l}\text { most commonly used clinical laboratory values. So if you have results of your laboratory } \\
\text { tests you can use this application to compare your results to the values set as } \\
\text { recommended guidelines for good health. Normal values and references are provided in } \\
\text { both Conventional Units (CU) and, whenever available, in units of the Sistme } \\
\text { International (SI). }\end{array}$ \\
\hline $\begin{array}{l}\text { Source:Quick Lab Ref, } \\
\text { May 2013 }\end{array}$ & $\begin{array}{l}\text { htps://play.google.com/store/apps/details?id=com.clinical.quicklabreference, accessed } \\
\text { Tool for health } \\
\text { support } \\
\text { from hospitals and medical research institutions to deliver online discussion boards on } \\
\text { healthcare topics. The tool can help patients manage their health. The tool gives people } \\
\text { access to description of over 1500 symptoms and treatments on a daily basis. Different } \\
\text { trackers are available on the website and on mobile phones through web-based browsers } \\
\text { and applications covering both general health conditions, such as weight loss and } \\
\text { allergies, and very specific disorders, such as infertility and diabetes. }\end{array}$ \\
\hline Source:MedHelp, http://www.medhelp.org, accessed May 2013 \\
\hline $\begin{array}{l}\text { Online community } \\
\text { for patient support }\end{array}$ & $\begin{array}{l}\text { This tool is an online community which provides patients with a way to share their real- } \\
\text { world health experiences in order to help themselves, other patients, and organizations } \\
\text { with managing various health conditions. On this network, people connect with others } \\
\text { who have the same disease or condition. People can track and share their own } \\
\text { experiences with others. The community can be accessed via website or via mobile. }\end{array}$ \\
\hline \multicolumn{2}{|l|}{ Source:Patients Like Me, http://www.patientslikeme.com, accessed May 2013 } \\
\hline
\end{tabular}

